\title{
Choice and consequence: A naturalistic analysis of least-worst decision-making in critical incidents
}

\author{
Neil Shortland ${ }^{1}$ (D) Laurence Alison ${ }^{2} \cdot$ Lisa Thompson ${ }^{1} \cdot$ Chloe Barrett-Pink $^{2} \cdot$ Lauren Swan $^{2}$ \\ Published online: 12 June 2020 \\ (C) The Psychonomic Society, Inc. 2020
}

\begin{abstract}
Individuals responsible for decision-making during critical incidents must wrestle with uncertainty, complexity, time pressure, and accountability. Critical incidents are defined as rare events where demand outstrips resources and where there are high stakes, uncertainty, and dynamic and ever-shifting elements that frustrate clear predictions. This paper argues that critical-incident decision-making is highly complex because many critical incidents have no such analogue, and thus there is no prior experience to draw upon. Further, while prescriptive models argue for a selection of a "best" outcome, rarely in critical incidents is there a "best" outcome and, instead, more likely a "least-worst" one. Most options are high risk, most will carry negative consequences, and many will be immutable and irreversible once committed to. This paper analyzes data collected from critical decision method interviews with members of the United States Armed Forces to explore the psychological processes of making (or not making) least-worst decisions in high-consequence situations. Specifically, and based on thematic analysis of interviews with those who have made least-worst decisions while serving as part of the Armed Forces, we identify a host of exogenous (external to the incident such as resources, political agendas) and endogenous factors (features of the incident itself-size, scale, duration) that affect the decision-making process. These factors have, to date, not been factored into theoretical models of how high-stakes decisions are made under conditions of uncertainty.
\end{abstract}

Keyword Decision-making $\cdot$ Decision inertia $\cdot$ Choice $\cdot$ Uncertainty $\cdot$ Least-worst decisions

When the Camp fire barreled toward this Sierra foothill town last Thursday morning, officials had a crucial choice to make right away: How much of Paradise should be evacuated? . . . So, this time, they decided not to immediately undergo a full-scale evacuation, hoping to get residents out of neighborhoods closest to the fires first before the roads became gridlocked. ... But it soon became clear that the fire was moving too fast for that plan, and that the whole town was in jeopardy. A full-scale evacuation order was issued at 9:17 a.m., but by then the fire was already consuming the town. (Serna, St. John \& Lin, 2018)

Neil Shortland

neil_Shortland@uml.edu

1 Criminology and Justice Studies, University of Massachusetts Lowell, Lowell, MA, USA

2 Institute for Risk and Uncertainty, University of Liverpool, Liverpool, UK
The above quote highlights a case of a critical decision made during the California wildfires, which resulted in a delayed evacuation and the death of 48 people. It appears that there was significant hesitation about when would be the most appropriate time for a full-scale evacuation, and the assumption that maybe this fire was not so bad that this approach would even be needed (until, of course, it was too late). Psychologists who study decision-making in high-stakes situations (military operations, counterterrorism operations, emergency response situations) have recognized this phenomenon. They argue that a failure to imagine the worst outcome (fire overwhelms town) and a failure to "accept" a bad outcome (full-scale evacuation) leads to the generation of a catastrophic outcome (fire overwhelms the town and we haven't evacuated) that they had not seriously contemplated (Alison et al. 2015; Shortland \& Alison, 2020; Shortland, Alison, \& Barrett-Pink, 2018; Shortland, Alison, \& Moran, 2019; van den Heuvel, Alison, \& Crego, 2012). It is easy to see how indecision and delay can occur in contemplating such options. For example, when responding to the Grenfell Tower fire in London in June 2017 (in which 72 people died), it was reported after the fact that a failure to evacuate immediately by the 
London Fire Brigade (LFB) may have made all the difference between life and death (Lane, 2017). In Grenfell, the "stay put" policy made sense for $99 \%$ of fires because asking people (many of whom were elderly or vulnerable) in a 24-story block to risk their lives by walking out of their apartment into smoke and stairwells with possible falling rubble could be life threatening. That may have been why the LFB hesitated going against the policy — even though it very evidently did not help the actual ground truth circumstances and led to the even worse alternative (all the people we could have tried to evacuate are now dead). Iterative indecision (shall we evacuate or not) continued until, just as with the town of Paradise, it was too late to consider evacuation.

Over the past several decades, many fields of study have concerned themselves with how we make decisions. Philosophers, mathematicians, economists, psychologists, and political scientists have all attempted to understand how people make decisions in the face of various situations, stimuli, and contexts (e.g., Payne, 1976; Plous, 1993). Yet, despite the interest in making and committing to a decision, there is a dearth of knowledge on not making a decision in the face of various situations, stimuli, and contexts (Anderson, 2003). And, specifically, very little attention has been paid to looking at why, how, and when decision makers fail to make a decision when, quite evidently, they should - since the option that they should (although bad) is still better than no decision at all.

In naturalistic decision-making, where findings generally come from observations conducted in the field (like the California Wildfire response or international crises such as the Syrian Civil war; Alison et al., 2018), researchers have called this type of decision-making "least-worst" (see Power \& Alison, 2017a, 2017b). Least-worst decisions are those in which every course of action could lead to negative consequences. Further, the decision maker anticipates that all outcomes appear aversive (or that choosing between the leastworst quickly is very difficult). Indeed, the often-considered hallmark of good decision-making - prospective evaluation of what each future outcome might look like - actually becomes a hindrance - since constant consideration of different options can result in not acting at all. And, as we have argued, that lack of decision-making results in the worst possible outcome.

Paradoxically, there is considerable cognitive effort involved in this form of decision inertia. As such, the form of inertia we are considering is different to decision avoidancewhere a choice is delayed, ignored, or deferred (outlined by Anderson 2003). In decision avoidance, contemplation is rejected in favor of worrying it through later, moving responsibilities for the decision elsewhere, or ignoring the issue altogether. The form of decision inertia we are concerned with is "redundant deliberation." In contrast to decision avoidance, redundant deliberation is cognitively demanding. It is defined as the persistent consideration of future options to a point beyond that persistence being of any help in dealing with current circumstances (Alison et al., 2015). As such, the concept of timing is critical. Redundant deliberation is therefore especially relevant in time-sensitive situations (e.g., economic, critical incident, foreign policy, military). Of course, in an ideal situation, we would want all the facts about a situation in order to have the most well-informed conceptualization of the size, scope, and shape of the problem. However, there may be circumstances in which we either can never know the full details, or in waiting to find out more, we get diminishing returns on time spent "searching" compared with time spent solving. This also separates decision inertia from the concept of hypervigilance proposed by Janis and Mann (1977). Hypervigilance involves poor decision-making due to the perception of insufficient time, while decision inertia involves the inability to decide at all within a given time frame. Redundant deliberation occurs between the "option generation" and "option evaluation" stage of decision-making.

Researchers are increasingly documenting and attempting to study decision inertia and the conditions under which it emerges (e.g., Alison et al., 2015; Power \& Alison, 2017a, 2017b; van den Heuvel et al., 2012). However, no research to date has explored the cognitive process that underpins least-worst decision-making, and only a handful of studies have researched the very specific but significant process of redundant deliberation (see Alison, Power, van den Heuvel, \& Waring, 2015). Indeed, something that we know nothing about presently is why, in the same situation, some individuals appear to be especially prone to redundant deliberation, while others push forward and commit. Given the lack of empirical research on this topic, in this research, we propose to explore the process of least-worst decision-making under conditions of high uncertainty.

\section{This study}

To date, no research has investigated the process that members of the Armed Forces (or anyone) go through when navigating least-worst decisions. Given this, this research sought to explore the manifestations of least-worst decisions in conflict and the barriers to effective least-worst decision-making as they emerged in the real world.

\section{Method}

\section{Participants}

We interviewed 27 current or veteran members of the U.S. Armed Forces. All had served on deployed duty in Afghanistan or Iraq since 2001 (and many had also served in other foreign theatres). Participants covered four major branches of the United States Armed Forces (Air Force, 
Army, Navy, and Marine Corps) and represented a range of ranks. Three participants were female $(11.11 \%)$, reflecting the gender split within the Armed Forces (16.19\% female; Department of Defense, 2016). Each participant was interviewed once, and each participant provided one leastworst decision, which they were asked to discuss in detail. On average, each interview lasted more than 1 hour (Median = 87 minutes 49 seconds, range: 96 minutes 18 seconds). Overall, these interviews resulted in 172,379 words of text related to their articulation of psychological process of making a least-worst decision. While all of the decisions discussed in this research occurred on deployment, the majority of the decisions discussed did not involve kinetic operations (60.87\%); that is to say that the least-worst decision-making that they faced did not involve a decision to take offensive action against a potential target. Instead, many of the least-worst decisions that were faced were logistical, and even personnel centered. To put this point in perspective, in our sample of soldiers, who had conducted multiple tours of duty and hundreds of in extremis kinetic operations, for many the decisions that they identified as challenging were not faced "at the point of death" but instead in the headquarters, or base camp (39.13\%) Interviews were conducted between March 2015 and September 2017.

It should also be noted that participation was voluntary, participants provided informed consent, and they were told that the purpose of the study was to gain insight on military decision-making and develop empirically based training for more effective decision-making.

\section{Critical decision method}

The critical decision method (CDM) interview is a cognitive task analysis method that seeks to understand decisionmaking in a specific (often unique) incident that individuals have faced in the real world. The CDM therefore provides a method of collecting, in retrospect, insight into practitioners' decision-making processes. The CDM helps practitioners "tell stories"; it is a single-incident-centric method and requires the participant to select and recall a single (ideally rare) incident in detail. In doing so, it allows researchers to gather information on the incident, the incidents' background, and the individuals' cognitive processes during the event (such as planning and sense-making). It also allows researchers to identify critical decision points. The CDM therefore develops rich and detailed data on the cognitive processes used by experts when responding to challenging events (Crandall, Klein, \& Hoffman, 2008). One of the distinct advantages of the $\mathrm{CDM}$, then, is that decisions are explored post hoc, rather than in situ, meaning that detailed data can be collected without putting the researcher (or, more importantly, the participant) in harm's way. In fact, the CDM was developed in part because of issues of collecting data on the decision-making of firefighters while "in action" (see Crandall et al., 2008).

The CDM has several benefits: It gives indications of the cues and patterns that experts perceive; "rules of thumb" they have devised; the kinds of decisions they are required to make; as well as features of tricky, typical, and rare decisions. The CDM involves an extensive (more than 2 hour) interview and has previously been used to elicit data points for decisionmaking in law enforcement officers (Harrington, Brown, Pinchin, \& Sharples, 2018), nurses (Crandall \& GetchellReiter, 1993), ambulance dispatchers (Wong \& Blandford, 2004), intelligence analysts (Hutchins, Pirolli, \& Card, 2004), pilots (Plant \& Stanton, 2013), diagnosticians (Islam, Weir, Jones, Del Fiol, \& Samore, 2015), ophthalmic surgeons (Pauley, Flin, \& Azuara-Blanco, 2013), and military command and control (Pascual \& Henderson, 1997).

The CDM interviews involve four "sweeps," each sweep using different types of probes and perspectives to facilitate the quality of recall (Crandall et al. 2006). The first sweep results in the selection of an incident that matches the requirements of the research and the goals for data collection. Usually, the CDM focuses on nonroutine decisions and challenging events because these have the greatest potential for uncovering aspects of a given cognitive phenomena. This is also important to ensure that the interview catches cognitive processes beyond procedural and routine knowledge, allowing insight into the characteristics of skilled and expert performance (Crandall et al. 2006). Once a candidate event has been identified, the interviewee is asked to recall the event from start to finish. The second sweep involves the participant developing a visual (or verbal) time line of the event. In developing a time line, participants were encouraged to highlight "critical points" within which the decision maker experienced a major shift in their understanding of an event, or an action was taken that changed the event (Crandall et al. 2006). During the second sweep, inconsistencies, gaps, and missing elements are also identified, allowing the interviewer and interviewee to arrive at a shared view of the facts. The third sweep involves "deepening," within which the interviewer uses a series of cues to investigate the practitioners' cognitive experience of the event (i.e., their expectations, mental models, assessment, and experience). The third sweep goes beyond the time line to seek out the participant's perceptions, expectations, goals, and uncertainties during the incident. During this sweep, the interviewer uses probes for additional information and elaboration from the participant. The final sweep of the CDM involves questioning the "what ifs" of an event. In this sweep, a series of probes aimed at identifying hypothetical factors (within the environment, or the decision maker) that would have resulted in a different outcome or experience (see Crandall et al. 2006, pp. 69-83). Our CDM interviews started with the following statement:

"I am going to be asking you in a moment to spend some time thinking about a decision that you had to make, 
while in the Armed Forces, in which you had to choose between one or more options and in which you spent a lot of time thinking about all the possible outcomes."

After the participant felt they had identified a situation that met these requirements, they would verbalize the situation (or situations) to the researcher. The researcher would check that (1) it met the criteria of a least-worst decision and (2) the participant would be comfortable talking about it, in detail, for up to 2 hours. This second criteria involved checking the participant's level of comfort and recall. If both criteria were satisfied, we proceeded with the four sweeps of the CDM. First, the participant outlined the event to ensure that it met with the requirement of the study. After this, the participant was asked to provide a time line (auditory, or visual through drawings) of the event identifying key decision points, key actors, key events, and outcomes. Next, the "deepening' began, in which (using a semistructured interview technique) we used a series of probes to further delve into the decision- making of the participant. The probes used in this part of the interview are outlined in Table 1 and are drawn from Crandall et al. (2006). Where possible, all probes were used for each participant; however, in some cases, the probe was irrelevant, and hence not asked. Finally, after deepening probes were exhausted, participants were asked a series of "what if" questions to explore what aspects of the situation, if changed, would have changed their decision-making.

\section{Data analysis}

The CDM interviews were transcribed, converted into anonymous units, and subjected to thematic analysis, a form of content analysis. Content analysis methods present and evaluate information in a systematic, objective, and reliable manner, allowing conclusions to be drawn from data that are rich in detail and applied to a particular context. Thematic analysis is defined as "a method for identifying, analyzing and reporting patterns (themes) within data. It minimally organizes

Table 1 CDM probes used to explore participants' decision-making strategies

\begin{tabular}{|c|c|}
\hline \multirow[t]{5}{*}{ Information } & What were you hearing/thinking/noticing during this situation? \\
\hline & What information did you use in making a decision or judgment? \\
\hline & How and where did you get this information, and from whom? \\
\hline & What did you do with this information? \\
\hline & Did you discard any information that you received? \\
\hline \multirow[t]{2}{*}{ Analogs } & Did this situation remind you of any previous experiences you have had? \\
\hline & What were the parallels you drew between the situation and others? \\
\hline Standard operating & Did this case fit a standard scenario? \\
\hline Procedures & Is this the type of event you were trained to deal with? \\
\hline \multirow[t]{2}{*}{ Goals and priorities } & What were your specific goals and objectives at this time? \\
\hline & What was the most important thing for you to accomplish at this point? \\
\hline \multirow[t]{3}{*}{ Options } & What other courses of action were considered? \\
\hline & What courses of action were not considered, and why? \\
\hline & Was there a rule that you were following in choosing this option? \\
\hline Experience & What specific training or experience was necessary or helpful in making this decision? \\
\hline Assessment & If you were asked to describe the situation to someone else at that point, how would you describe it? \\
\hline \multirow[t]{4}{*}{ Mental models } & Did you imagine the possible consequences of this/these action(s)? \\
\hline & Did you create some sort of picture in your head? \\
\hline & Did you imagine the events and how they would unfold? \\
\hline & How close was your imagined outcome to the actual outcome? \\
\hline \multirow[t]{5}{*}{ Decision-making } & What let you know that this was the right thing to do at this point in the incident? \\
\hline & How much time pressure was involved in making this decision? \\
\hline & Did you think about it for too long? \\
\hline & Were you ever worried about the time it was taking to make the decision? \\
\hline & How long did it take to actually make this decision? \\
\hline \multirow[t]{2}{*}{ Guidance } & Did you seek any guidance at this (or any) point in the decision? \\
\hline & How did you know to trust the guidance you got? \\
\hline \multirow[t]{2}{*}{ Feelings } & How did making this decision make you feel? \\
\hline & How did you feel about potentially making the wrong choice? \\
\hline
\end{tabular}


and describes your data set in (rich) detail" (Braun \& Clarke, 2006 , p. 79). Quantities of diverse data, such as that collected here, can be minimally organized, yet described in rich detail (Braun \& Clarke, 2006), and common themes can emerge independently from word frequencies (Hsieh \& Shannon, 2005; Simons, Lathlean, \& Squire, 2008). Here, the thematic analysis followed the step-by-step procedure provided by Braun and Clarke (2006). It was performed using the qualitative analytical software NVivo 10 (Gibbs, 2002).

The first stage of analysis involved establishing "codes" within the data. Codes identify a feature of the data (both semantic and latent content) that is of interest. Codes are "the most basic segment, or element, of the raw data or information that can be assessed in a meaningful way regarding the phenomenon" (Boyatzis, 1998, p. 63). For example, if we consider the following utterance: "So, if you have a carbomb that goes off in close proximity, or there is someone that blows a building up and it goes crashing down, uh, then as a commander I have responsibility to find all the personnel, find all the sensitive items, get everything back out of there," we can identify that there are several codes (sensitive items, retrieval of materials, close proximity), but a central one is "responsibility." Codes are then grouped together into "themes," in which these codes are inspected for consistent informational threads (recurrent elements of narratives) and clustered together to form coherent themes. For example, in the abovementioned utterance, based on the frequency and depth of utterances that focus on responsibility (i.e., different types of responsibility), we may develop a theme of "responsibility" that encompasses several types of code for responsibility. Interrelation between themes was also considered to identify candidate themes and subthemes. The accuracy of the thematic analysis was then tested by providing a sample of codes and a list of all codes that had been identified to an additional researcher, also trained in qualitative analysis, to provide a metric of intercoder reliability. Interrater reliability in this research was high (kappa $=0.81)$.

\section{Methodological limitations: Post hoc "bolstering"}

When considering these results, it is important to highlight the issues associated with analyzing recalled accounts of decisionmaking (e.g., Nisbett \& Wilson, 1977). This is especially relevant when we focus on hard choices that involved cognitive conflict because, as highlighted by Janis and Mann's (1977), individuals often retrospectively "bolster" the perceived benefit of one choice while minimizing the costs of the other. What this means is that the participants likely diminished the losses from the option that were turned down while increasing (or bolstering) the benefits of the one they chose. As such, the decision maker increases the differentiation of options to a greater degree than they are in reality (referred to as the "spreading of alternatives"; Janis \& Mann, 1977, p. 82).
Both experimental and field studies have shown that after someone commits to an action, they are likely to bias their perception in a way that increases the benefits of that choice (e.g., Brehm \& Cohen, 1962). What this means, then, is that when asking participants to recall a situation that, by nature, involves equally bad options, they are likely to have bolstered their perception post hoc to minimize the potential losses that could have occurred from the choices that they did not make. It is also important to note that this sample was convenience sampled, meaning that the individuals cannot truly be generalized. Additionally, operations in Afghanistan and Iraq have occurred in a certain ecological niche, meaning that we should be cautious when proactively, or even retroactively, applying these findings to other contexts.

\section{Results}

\section{The manifestation of least-worst decisions}

All participants were able to recall a least-worst decision that they have faced on deployment $(100 \%)$. Furthermore, when identifying or discussing the decision, most emphasized that it was one they "always talked about" or had "stuck with them." This illustrates that these though these events may be rare within the armed forces personnel, most will have encountered a decision environment in which neither doctrine, policy, experience, nor training can directly assist them. In some instances, participants recalled incidents from their last deployment $(<1$ year since the incident), and in others the participant recalled incidents from deployments in the earliest days of the "war on terror" (>17 years since the incident). While we are aware of the abovementioned limitations, the degree of detail in the participants' recall, so far postevent, supports the subjective importance of these incidents for the decision maker.

Below, we present a sample least-worst decision to demonstrate what least-worst decisions look like, as experienced by the decision maker:

I'm sitting there getting everybody consolidated, reorganized, and distributing ammo, because we didn't know if there was gonna be another attack or what was going on, and we had the civil affairs major came up to me and he said "I want you to pursue the enemy. I want you to go up into the mountains and get a body count and pursue the enemy." And I looked at him and I said, "Are you kidding me?" And of course we were all standing around the top of this little hill mountain that we were on where this medical clinic was no bigger than this room right now and we were in the middle and everybody was kinda around, getting stuff ready, and you know. . . I said, "We're not gonna do that. We're gonna consolidate and reorganize, we're gonna 
distribute ammo and we're gonna get the hell out of here. We still have to make it out of this canyon. They let us in, but it doesn't mean that they're gonna let us out. And frankly, we don't have the force to pursue the enemy. "I mean, at the time we didn't know how big they were, we didn't get the intel reports and stuff back until later, but it was clear that they were outnumbered and damn near overrun but for the close air support. And he said, "Captain, I'm not asking you, I'm giving you an order; you will go into the mountains and get a body count and pursue the enemy." Talk about paralysis by analysis, there was no paralysis here. For a split second I thought, "This is it, this is my military career". . . and I said, "Well, Sir, here's what's gonna happen; the people that are wearing this patch" [pointing at his own arm] — which was everybody there expect for the civil affairs team which were probably 6 guys-I said, "Everybody that is wearing this patch is gonna get in their vehicles and we're gonna get the $f$-out of here because this is not a safe place to be. And the people wearing that patch [pointing at the civil affairs Major's arm] can stay here and follow you into the mountains." And at which point he got right in my face, very irate. The guy had a temper problem. He was just extremely irate, you know, swearing at me telling me that I was disobeying a direct order and he was gonna bring me up on charges, and I just looked at him and said, "Well, you do what you have to do, Sir, and I'll do what I have to do." And I looked over to my Platoon Leader and I said, "Mount up; let's get the $f$ - out of here," and everybody got in their vehicles, including the Major, who was, umm, the civil affairs major, and we rolled out of there. ... My decision-making process there took about 30 seconds. Long enough for me to think. . . literally, I disobey this order I'm taking my 10-year career and throwing it in the garbage. But again, this was a split-second decision for me because at the end of the day, I remember thinking to myself I would rather lose my commission, you know, be fired and find another job and have everybody there that was with me make it back home than, you know, make the wrong decision and follow an order that I knew was tactically unsound and lose my Soldiers and/or my life. So, I don't think that process took very long; I guess long enough for me to kind of kinda have that conversation in my mind.

Here, the individual must decide between (1) obeying a direct order and leading a mission into the hills of Afghanistan, and (2) disobeying a direct order and returning to base. Again, as stated earlier, what is key here is that both options could have had either positive or negative consequences. For example, the second option could result in (1) being fired and ending a decade-long military career, or (2) safely returning all troops to the base and experiencing no negative consequences. For context, we also outline a series of other example cases in Table 2.

\section{"Unique" decisions}

Overall, 20 of the 27 participants (74.07\%) referenced an aspect of the decision that was unique. That is, they considered this a problem where there was either no policy or the

Table 2 Sample decisions

\section{Decision outline}

A soldier goes outside the wire to meet a "walk-in" (an individual who offers potential intelligence). When meeting the walk-in, a sports utility vehicle (SUV) pulls towards them aggressively. Decision maker must decide if this is a vehicle-bourne improvised explosive device (IED), or not and the soldier is placed in a shoot/don't shoot scenario.

A convoy driver is providing rear-security to convoy carrying gas to second base. He/she encounters a civilian driver acting in an aggressive manner. After this situation is diffused, as they proceed, a car approaches them at a very fast speed (could be a vehicle-bourne IED; VB-IED). Gunner fails to act, forcing convoy driver to take action to intercept this potential VB-IED and protect the convoy.

A driver sets out on convoy, plans a route, and leaves the base. On the route they find that the routes they had planned (Routes A, B, and C) are all unavailable to them. While at the roundabout, the team leader had to decide (1) do we pull over and decide on a new route (making them a target); (2) go down Route D (a known hot-bed of insurgent activity that would very likely end up in a firefight); or (3) turn around and go back the way they came (which is heavily frowned upon, as once you have travelled a route, insurgents often lay IEDs ready for your next trip through).

A drone pilot was charged with determining whether ambiguous activity they could witness through their feeds was "hostile" (i.e., embedding an IED) or nonhostile (i.e., digging for fruit). If decided hostile, they would engage, potentially causing civilian casualties; if hostile and they didn't engage, they could be leaving fellow soldiers at risk.

A marine commander was required to decide if they can and should set up an indigenous force in their local area. There were many benefits to doing this; however, in doing so they would open that area (and the civilians in it) to enemy targeting.

A contractor is driving a very large piece of military equipment through a hostile village. The equipment (a very large truck) is hit with a rocket propelled grenade (RPG). The contracted driver flees the scene, leaving a large, flaming truck in the middle of the village. The interviewee was tasked with retrieving this truck because it is causing an issue for the local population. Three failed attempts are launched, and the longer the truck remains where it is, the greater the chance that it will be used as an insurgent trap. Also, the longer it is there, the more likely it is to become enemy propaganda.

A pilot is mid-air and having to refuel; however, the refueling jet is not in place, leaving them in the position where they have to decide between continuing to try and refuel mid-air, which could result in them running out of fuel and having to land in hostile territory, or bailing out and abandoning the mission.

A scientist detects a flaw in an algorithm for imminent mission flight. They have to decide if they should raise concerns and the implications of doing so. 
prevailing circumstances did not enable a clear policy solution and they had no previous experience to draw upon to help inform or guide their decision. Thus, they considered either the situation to be completely unique (i.e., not a common decision for any soldier to experience; $65 \%$ ), or at least unique to them (but might have been experienced by other soldiers more commonly in another role; 35\%). When looking at the overlap of "uniqueness" and "least-worst" decisions, it is important to consider the types of decisions they were trained for. Members of the Armed Forces are trained to make fast and accurate decisions in war (Matthews, 2013). Several models (such as the Military Decision-Making Process, or OODA [Observe, Orient, Decide, Act] Loop Framework; Boyd, 1996) have been developed to assist members of the Armed Forces to "apply critical and creative thinking to understand, visualize, and describe unfamiliar problems and approaches to solving them" (ADP 5-0. U.S. Armed Forces, 2012). However, the domains (and scenarios) within which these decision-making strategies are trained are often routine - that is, they test and train individuals with the types of tasks and missions that reflect the types of task and mission that they will be required to perform repeatedly during their future operations. On the other hand, least-worst decisions are, by their very nature, often rare, atypical events that are dissimilar to situations previously faced by the decision maker. This means that the majority of decisions recalled as part of this study were demanding specifically because they were completely different to the types of decisions made in training. As one of our interviewee's (a drone pilot) stated:

\section{Interviewer: So how did this decision differ to the ones you'd faced in training? Interviewee: Training is easy, you know, you just do it; you're given missions without thought and you're not giving, you're never given sce- narios where Afghans may be doing this, or they may not. Go look at this, find this, do this, get a beer after or a steak dinner. It's not like this where you live on a base that's getting rocket attacked and stuff. Everything plays into it. There were a few times we were wearing our gear while we were flying because we were getting attacked. Nothing training can do.}

Linked to this point was the finding that in all cases discussed here, the decision (for one reason or another) was "unique," meaning that the decision maker had not faced (in the real world or training) a decision like this. Currently, the military (in line with recognition-primed decision-making perspectives [RPD]) attempts to support soldiers' decisionmaking by developing their pattern-recognition capability through exposing soldiers to increasingly complex missions, aimed at building "his or her own library of experiences that can ultimately be tapped into when an intuitive decision is called for" (Matthews, 2013, p. 67). But in this research, the decisions that participants faced did not match the "library of experience" they had developed through prior deployments and training. As one participant recalls:

This particular situation was unique, and, especially where we had two things happen one after another, I mean, this is 2010. This is when the whole drawdown was going on any everything, does it compare, from what other people told me, these were pretty quiet times, except you would have your spurts every now and then, and this was a lot a precursor to ISIS and everything, they were fighting amongst each other and less against us, I think we were just waiting it out. But yeah, I uh, yeah, I this was really a unique situation, I cannot think of another situation where it was like this, this was the only one I had to write a statement on! So, yeah, I mean, we'd had trucks try to force their way into our convoys, but never like this.

The point is that doctrine and policy can only get you so far, and that experience and expertise - though, of course, crucial, also has its limits. In these least-worst, never-before encountered unique events, different processes come into play.

\section{Endogenous uncertainty}

Endogenous sources of uncertainty include ambiguous information, time pressure, and risk (Orasanu \& Connolly, 1993). They prevent the decision maker from developing situation awareness (i.e., "what is going on") and increases the challenges with prospectively modelling outcomes of an action (i.e., "what will happen if"; Klein, Snowden, \& Chew, 2007). Overall, more than half $(55.56 \%)$ of the participants specifically mentioned endogenous uncertainty as a barrier to their decision-making; meaning that the uncertainty in the situation created a least-worst decision because the decision maker did not have enough situational awareness to be able to effectively project the likely outcome of an action. Instead, they could only project the outcome of two, very different outcomes, both of which were often in conflict. One soldier recounts:

Now, at this point, and you talked earlier about a point at which there was no good decision, I don't know what their intent is, I know they are coming straight at my guys, at my friend, um, and I don't know what I am supposed to do, right? I don't know if this guy is a danger or not. And I also don't know, with an SUV you've got a fair amount of cargo capacity there, so I'm thinking this could also be a bomb? So, inside my head, I am thinking, "He's going to die," this guy is going to blow himself up, because, just the way he came out, he really 
tore his way out of that parking lot and came right at them . . and there was a split second when I thought I can save [the walk in's] life right now by possibly murdering an innocent person. And on the other side of it, and I had to weigh that against, do I want my friend to possibly be killed, and at the same time I'm thinking, it's possible that if I shoot at this guy, it isn't going to save my friend anyway, right?

The finding that uncertainty in the situational awareness is directly related to Lipshitz and Strauss' (1997) work with members of the Israeli Defense Forces Command and General Staff College. Lipshitz and Strauss asked soldiers to "write a case of decision making under uncertainty from your personal experience in the I.D.F." (p. 154). Their results showed that the two most common sources of uncertainty were that they inadequately understood the situation (24.6\%), and they were conflicted by having two alternatives with equally attractive (or unattractive) outcomes (24.6\%; p. 156). It is clear, however, that these two issues are causally linked in many cases. A poor understanding of the situation can create the perception of equally unattractive outcomes because the decision maker is unable to prospectively and accurately visualize the outcome of a given course of action. By not being able to visualize potential outcomes, it then makes it very hard for the decision maker to engage in ensuing RPD processes such as option selection because, without knowing (with any degree of certainty) what the outcome of decision will be, the decision maker cannot identify if it is "satisfactory" or "workable."

\section{Exogenous uncertainty}

The U.S. Army Human Dimension Strategy (2015) emphasizes development of "Soldiers and Army Civilians who are not just comfortable with ambiguity and chaos, but improve and thrive in even the most difficult conditions and achieve mission success" (p. 4). But, very rarely do we discuss the issues of uncertainty that stem from within a team, organization, or culture that operates within an uncertain environment. Endogenous sources of uncertainty include ambiguous information, time pressure, and risk (Orasanu \& Connolly, 1993). They prevent the decision maker from developing situational awareness (i.e., "what is going on") and, as we argued above, affects the ability of decision makers to prospectively model outcomes of an action (i.e. "what will happen if'; Klein et al., 2007). Exogenous uncertainty, on the other hand, derives from confusion over both one's own expectations and their expectations of another's performance (van den Heuvel et al., 2012). Exogenous uncertainty can derail teamwork by affecting team cohesion, and reducing team members' willingness to share (McKay, 1991) or seek information with other partners (Sniezek \& Van Swol, 2001). In several cases collected as part of this study, the decision maker had to deal not only with endogenous uncertainty but also exogenous uncertainty surrounding the roles and actions of other members in the decision-making team. In this sample, more than two-thirds $(66.67 \%)$ mentioned a source of exogenous uncertainty that influenced their decision-making. For example, participants were either forced to make a least-worst decision because of role confusion, or the actions of others (e.g., "One of the reasons I was forced to do something in this situation was because the gunner didn't . ..."). In other cases, they struggled to make a decision due to uncertainty stemming from the actions of others:

It was frictional, I mean even us going and asking, they have their own priorities and missions, and this is just a distraction for us. We almost had to go through another unit to get to even set up direct communications with them. And that's hard, just the communications piece. [At one point] I flew a guy up there just to have a faceto-face meeting. . . . So that was kind of the interaction with the Poles, all of which had to be done though interpreters.

Hence, our data support that uncertainty generates leastworst decision by creating outcome uncertainty, and that exogenous uncertainty can further hinder the decision-making process by introducing issues of role confusion, lack of cohesion, and distrust - all of which create further barriers to decision-making. The fact that exogenous uncertainty was mentioned more than endogenous uncertainty also questions the overarching focus on external sources of uncertainty on decision-making, rather than internal sources of uncertainty.

\section{Organizational pressures}

In addition to uncertainty, half of our participants (50\%) referenced the role of organizational pressures such as accountability and "blame culture" on their decision-making. In decision-making, future accountability influences choice. Individuals feel accountable for a decision when they are being appraised by external audiences (Klehe, Anderson, \& Hoefnagels, 2007); can be rewarded or punished (Baucus \& Beck-Dudley, 2005); when actions will be linked back to them; and when they will have to justify or explain these actions (de Kwaadsteniet, van Dijk, Wit, De Cremer, \& Rooij, 2007). Naturalistic decision-making research has shown that accountability increases cognitive load (Tetlock \& Boettger, 1989) and, in a simulated counterterrorism operation conducted by van den Heuvel et al. (2012), accountability shifted the decision makers' priorities away from saving the lives of those in (potential) attack location to saving oneself (i.e., making decisions that would not result in blame after the fact). Accountability therefore increases self-preservation 
and can distract attention from the task and towards impression management (Waring, Alison, Cunningham, \& Whitfield, 2013). To date, little research has explored the influence of accountability on military decision-making, even though military culture "vests considerable authority, responsibility, and accountability with the commanding officer" (Broedling, 1981, p. 91). Furthermore, Gow (2013) highlights that the rise of social media goes "hand in hand with the proliferation of international criminal tribunals, stirring intense debate over boundaries between right and wrong, legal and illegal, in contemporary warfare." Accordingly, several participants highlighted both the role that organizational pressures played in both the way in which they made a decision, and specifically, the course of action that they chose. As highlighted by one interviewee:

The culture at the time was a fault-intolerant culture, right, they were more worried about whether you followed the procedure right, um, than whether they were setting you up for paranoia. Your paranoid about the Afghans as much as you were about your boss coming down on you ... so, yeah, that was absolutely in my thought process, everything there was about, you know, trying to prevent bad things from happening - they were less worried about that it seemed to me that they were about accomplishing the mission, so I'm, at this point I'm a major, I'm a field grade officer, I know my Sun $T z u$, and my Clausewitz, and things like that, and I know, as they said, "all war's political." War is an extension of politics by other means, that the real way you win this war, like Sun Tzu said, is to win the hearts and minds of the people, and so it is frustrating to me, this is a side, unrelated to the decision-making, but it is frustrating to me to be in an environment when they are not interested in engaging with the Afghan people, going out and making tribal alliances, and making friends, they were more worried about "let's not screw anything up." Let's not do anything wrong, right?

Regarding the latter point, CDMs also highlighted that in several cases decisions were made not because they were perceived as the "best" (or even "least-worst" cause of action) but because of organizational pressures that affected the choices that a soldier made. This means that we have very few empirical examinations of the role and extent to which exogenous and endogenous factors play a role in critical incident decisions. Here, the CDM was able to highlight the role of factors that are unlikely to emerge in general interviews, or scenario-based Trainings (SBTs; see Alison et al., 2013), such as organizational pressures. This reinforces the void between our theoretical perspectives of military decision-making and the factors that can influence the way military decisions are made on deployment.

\section{Discussion and theoretical implications}

Recognition-primed decision-making relies heavily on the experience of the decision maker, specifically as it pertains to their ability to match the current situation to a familiar decision they have experienced in the past (Klein, 1997). This process of pattern matching allows for rapid, accurate, and effective critical decisions. However, this is not the full picture. The issue identified in the interviews above is that the diversity and complexity of least-worst decisions (in this case those experienced in a contemporary conflict environment) means that U.S. Armed Forces are likely to struggle with situations in which they have no "analogous" experience. In this research, the more members of the Armed Forces we interviewed, the more often we heard that the least-worst decision they faced was something they had "never experienced before," and for which they had no "analogies" that they could apply, nor training that they could draw upon to help them decide what to do. The following is prototypical in this sense:

This particulate situation was unique, and, especially where we had two things happen one after another, I mean, this is 2010. This is when the whole drawdown was going on and everything ... these were pretty quiet times. ... But, yeah, this was really a unique situation; I cannot think of another situation where it was like this.

In these instances, decision makers have to adopt an alternative form of decision-making. In Cohen and Lipshitz's (2011) proposed trimodal theory of decision-making, these decisions most closely resemble their third choice-based decision-making. "Trimodal" refers to three methods of choosing between various courses of action. ${ }^{1}$ The first is "matching," which follows a set of "if A, then B" rules. So, if the situation is perceived as an "if A, then B" scenario, the decision makers pathway is clear, and choice flows from what is akin to rulebased decision-making, policy, and doctrine. The second form of decision-making is reassessment. In reassessment, the decision maker asks, "Is my course of action reliable?" (Cohen \& Lipshitz, 2011, p. 10). Reassessment is the closest of the three to RPD. The final form of decision-making proposed by Cohen and Lipshitz is choice. Choice involves the commitment to choose one course of action over another, while having no preexisting commitment to either (Cohen \& Lipshitz, 2011, p. 11). While most clearly aligned to the choice aspect, the issue remains that the majority of decision-making training is based on the idea that relying on choice can be avoided either by (1) providing comprehensive policy or (b) training individuals to have a library of experiences to draw upon

\footnotetext{
${ }^{1}$ Cohen and Lipshitz $(2011$, p. 4) refuted the idea of a decision as a choice between two options, and instead argued that decisions are "graded commitments of mental, affective or material resources to courses of action."
} 
(RPD). Moreover, there are even instances where choice may come into play during anomalous instances of "matching" and where policy is not fit for purpose given prevailing circumstances.

What our work highlights is that for decision makers in the face of least-worst decisions, the unique nature of many decisions creates an environment in which they must engage in a more adaptive, potentially creative and value-based set of adaptations and in which very careful consideration is given to time as a critical factor. This requires rapid identification of the following: (i) this does not conform wholly to what I know about policy/doctrine; (ii) I have not seen something like this before; (iii) can I afford to wait and gather more information to be sure that what I am experiencing is what I think it is; and (iv) am I now at risk of losing the benefit of increasing my understanding of the situation against the requirement of actually solving it.

Further, considered through a traditional decision-making lens, choice normally involves selecting the best course of action rather than appropriately timed consideration of leastworst decision-making. As such, all of the above time-critical considerations must be made against the possibility of identifying the least-worst option rather than the best overall outcome. Recent evidence of this phenomena was shown by van den Heuvel et al. (2012), who reported in the presence of exogenous and endogenous uncertainty that "teams were not implementing critical decisions that they should have made in a timely manner, potentially culminating in detrimental consequences for the investigation" (p. 181). Instead, van den Heuvel et al.'s study found that effective decisions were delayed through either "nonactions" (not making a decision) or apparent actions that led nowhere (deferring choices or passing issues onto other agencies). To be clear, the work presented here is most certainly aligned to the naturalistic decisionmaking (NDM) thinking since we would expect, for example, experts to be able to recognize that the current and unique critical incident that they are dealing with does not fit doctrine or that they have not seen it before and that some but not all of their expertise can be utilized. Novices would, for example, not know that they should or should not recognize the situation. As such, the current paper builds upon rather than stands in contrast to NDM models. What, then, of more traditional approaches to decision-making?

Todd \& Girgerenzer (2001) argue that NDM perspectives avoid detailed theorization due to the (they argue, mistaken) belief that decision-making processes in high-stakes environments cannot be modeled, precluding the development of detailed hypotheses (see also Serfaty et al., 1997). However, we argue that our findings provide many potential experimental pathways for future research to explore the both the effect of the identified variables (time-critical factors, uniqueness, exogenous uncertainty, endogenous uncertainty, and organizational pressure) on the process of least-worst decision-making and the outcomes of decision-making both in terms of the choice made. We are respectful and supportive of the idea that lab-based experimental studies may assist in the identification of redundant deliberation and how, why, when, and where it occurs, as well as possible neurophysiological underpinnings associated with anticipation, regret, and innovation/adaptation. For example, based on the decisions identified in this sample, the authors developed a laboratorybased battery of least-worst decisions (Least-Worst Uncertain Choice Inventory for Emergency Responses [LUCIFER]; Shortland, Alison, \& Thompson, 2020), and using this method have been able to explore group-based differences in leastworst decision-making (e.g., soldiers vs., civilians) as well as the effect of personality traits such as maximization and need for closure (Shortland, 2017). This research method can also be used in the future to explore how the presence of one (or more) of the factors identified in this research may increase the amount of delay present in decision-making (van den Heuvel et al., 2012); it may also lead to choices being made that favor saving the self (i.e., avoiding blame) rather than prioritizing the needs to help others.

Thus, this research allows, at least, the preliminary development of experimental hypotheses that can be subject to quantitative analyses to develop theories pertaining to how, in the presence of high-uncertainty decisions, individuals commit (or do not commit) to a least-worst choice.

\section{Conclusions}

In this paper, we have sought to (i) understand the ecological niche within which critical least-worst decisions are made by individuals operating in extreme environments and (ii) appreciate that in such environments there is a very real risk of redundant deliberation leading to catastrophic outcomes instead of the least-worst one. However, this is only the first step. Here, we have identified the importance of a host of factors that are not currently fully incorporated into models of high-stakes decision-making (in this case, military decision-making). We argue that our theoretical lens must thus be widened to consider these wider issues that pertain to time, adaptation, and calculation, or least-worst rather than optimal outcomes. But this paper also tells a wider story of the complexity and consequences of real-world decision-making (especially least-worst decisions), which current theories do not yet fully address. Beyond rational choices, and recognitionprimed decisions, there are a host of - albeit fare more rare but arguably more significant-decisions that require commitment to an unknown outcome, that are affected by a wide 
range of pressures, and which, if handled badly, can be catastrophic both economically and in terms of human suffering.

\section{Open practices}

Neither of the experiments reported in this article was formally preregistered. Neither the data nor the materials have been made available on a permanent third-party archive; requests for the data or materials can be sent via email to the lead author (neilsshortland@uml.edu).

\section{References}

Alison, L., van den Heuvel, C., Waring, S., Crego, J., Power, N., Long, A., \& O'Hara, T. (2013). Immersive simulated learning environments for researching critical incidents: A knowledge synthesis of the literature and experience of studying high risk strategic decision making. Journal of Cognitive Engineering and Decision Making, 7(3), 255-272.

Alison, L., Palasinski, M., Waring, S., Humphrey, A., Humann, M., Shortland, N., \& Bowman Grieve, L. (2018). Between a rock and a hard place of geopolitically sensitive threats-critical incidents and decision inertia. Behavioral Sciences of Terrorism and Political Aggression, 10(3), 207-224.

Alison, L., Power, N., van den Heuvel, C., Humann, M., Palasinksi, M., \& Crego, J. (2015). Decision inertia: Deciding between least-worst outcomes in emergency responses to disasters. Journal of Occupational and Organisational Psychology, 88(2), 295-321.

Alison, L., Power, N., van den Heuvel, C., \& Waring, S. (2015). A taxonomy of endogenous and exogenous uncertainty in high-risk, high-impact contexts. Journal of Applied Psychology, 100(4), 1309.

Anderson, C. J. (2003). The psychology of doing nothing: forms of decision avoidance result from reason and emotion. Psychological Bulletin, 129(1), 139.

Baucus, M. S., \& Beck-Dudley, C. L. (2005). Designing ethical organizations: Avoiding the long-term negative effects of rewards and punishments. Journal of Business Ethics, 56, 355-376.

Boyatzis, R. E. (1998). Transforming qualitative information. Cleveland, OH: SAGE Publishers.

Boyd, J. R. (1996). The essence of winning and losing. Retrieved from http://www.d-n- i.net/fcs/ppt/boyds_ooda_loop.ppthttp://www.d-ni.net/fcs/ppt/boyds_ooda_loop.ppt

Braun, V., \& Clarke, V. (2006). Using thematic analysis in psychology. Qualitative Research in Psychology, 3(2), 77-101.

Brehm, J. W., \& Cohen, A. R. (1962). Explorations in cognitive dissonance. New York, NY: Wiley.

Broedling, L. A. (1981). The psychology of leadership. In J. H. Buck \& L. A. Korb (Eds.), Military leadership (pp. 71-94). Beverly Hills, CA: SAGE Publications.

Cohen, M. S., \& Lipshitz, R. (2011). Three roads to commitment: A trimodal theory of decision making (Unpublished manuscript).

Crandall, B., \& Getchell-Reiter, K. (1993). Critical decision method: A technique for eliciting concrete assessment indicators from the "intuition" of NICU nurses. Advances in Nursing Sciences, 16(1), 4251.

Crandall, B., Klein, G., \& Hoffman, R. R. (2006). Working minds: A practitioner's guide to cognitive task analysis. Cambridge, MA: MIT Press.
Crandall, B., Klein, G., \& Hoffman, R.R. (2008). Working minds: A practitioner's guide to cognitive task analysis. Cambridge, MA: MIT Press.

de Kwaadsteniet, E. W., van Dijk, E., Wit, A., De Cremer, D., \& de Rooij, M. (2007). Justifying decisions in social dilemmas: Justifying pressured and tacit coordination under environmental uncertainty. Personality \& Social Psychology Bulletin, 33(12), 1648-1660.

Department of Defense. (2016). 2016 Demographics: Profile of the military community. Office of the Deputy Assistant Secretary of Defense for Military Community and Family Policy, Department of Defense.

Gibbs, G. (2002). Qualitative data analysis: Explorations with nVivo. Buckingham, England: Open University.

Gow, J. (2013). War and war crimes. New York, NY: Columbia University Press.

Harrington, K., Brown, M., Pinchin, J., \& Sharples, S. (2018). Decision making within missing person search. Cognition, Technology \& Work, 20(4), 665-680.

Hsieh, H., \& Shannon, S. E. (2005). Three approaches to qualitative content analysis. Qualitative Health Research, 15(9),1277-1288.

Hutchins, S. G., Pirolli, P. L., \& Card, S. K. (2004). A new perspective on use of the critical decision method with intelligence analysts. Paper presented at the Ninth International Command and Control Research Symposium (ICCTRS), San Diego, CA.

Islam, R., Weir, C. R., Jones, M., Del Fiol, G., \& Samore, M. S. (2015). Understanding complex clinical reasoning in infectious diseases for improving clinical decision support design. BMC Medical Informatics and Decision Making, 15(1), 101.

Janis, I. L., \& Mann, L. (1977). Decision making: A psychological analysis of conflict, choice and commitment. New York, NY: Free Press.

Klehe, U., Anderson, N., \& Hoefnagels, E. A. (2007). Social facilitation and inhibition during maximum versus typical performance situations. Human Performance, 20(3), 223-239.

Klein, G. (1997). The recognition-primed decision (RPD) model: Looking back, looking forward. Naturalistic Decision Making, 285-292.

Klein, G., Snowden, D., \& Chew, L. P. (2007). Anticipatory thinking. Paper presented at the 8th International NDM Conference, Pacific Grove, CA.

Lane, B. (2017). Grenfell Tower-fire safety investigation: The fire protection measures in place on the night of the fire, and conclusions as to: the extent to which they failed to control the spread of fire and smoke; the extent to which they contributed to the speed at which the fire spread. London: Grenfell Tower Inquiry.

Lipshitz, R., \& Strauss, O. (1997). Coping with uncertainty: A naturalistic decision making analysis. Organizational Behavior and Human Decision Processes, 69(2), 149-163.

Matthews, M. (2013). Headstrong: How psychology is revolutionizing war. New York, NY: Oxford University Press.

McKay, J. (1991). Assessing aspects of object relations associated with immune function: Development of the affiliative trust-mistrust coding system. Psychological Assessment, 3(4), 641-647.

Nisbett, R. E., \& Wilson, T. D. (1977). Telling more than we can know: verbal reports on mental processes. Psychological Review, 84(3), 231-295.

Orasanu, J., \& Connolly, T. (1993). The reinvention of decision making. In G. A. Klein, J. Orasanu, R. Calderwood, \& C. E. Zsambok (Eds.), Decision making in action: Models and methods (pp. 3-20). Norwood, NJ: Ablex.

Pascual, R., Henderson, S. (1997). Evidence of naturalistic decision making in military command and control. In G. K. Caroline \& E. Zsambok (Eds.), Naturalistic decision making (pp. 217-226). Mahwah, NJ: Erlbaum.

Pauley, K., Flin, R., \& Azuara-Blnco, (2013). Intra-operative decision making by ophthalmic surgeons. British Journal of Ophthalmology, 97(10), 1303-1307. 
Payne, J. W. (1976). Heuristic search processes in decision making. Cincinnati, OH: ACR North American Advances.

Plant, K. L., \& Stanton, N. A. (2013). What is on your mind? Using the perceptual cycle model and critical decision method to understand the decision making process in the cockpit. Ergonomics, 56, 12321250 .

Plous, S. (1993). The psychology of judgment and decision making. Washington, DC: Mcgraw-Hill Book Company.

Power, N., \& Alison, L. J. (2017a). Offence or defence? Approach and avoid goals in the multi-agency emergency response to a simulated terrorism attack, Journal of Occupational and Organizational Psychology, 90(1), 51-76.

Serfaty, D., MacMillan, J., Entin, E. E., \& Entin, E. B. (1997). The decision-making expertise of battle commanders. Naturalistic Decision Making, 233-246.

Power, N., \& Alison, L. J. (2017b). Redundant deliberation about negative consequences: Decision inertia in emergency responders. Psychology, Public Policy, and Law, 23(2), 243.

Serna, J., St. John, P., \& Lin II, R. (2018, November 15). As California's deadliest wildfire closed in, evacuation orders were slow to arrive. Los Angeles Times. Retrieved from https:/www.latimes.com/local/ lanow/la-me-paradise-fire-evacuations-20181114-story.html

Shortland, N. D. (2017). Conflict: sacred values, decision inertia and the psychology of choice in military decision-making. (Doctoral Dissertation, University of Liverpool).

Shortland, N. D., \& Alison, L. J. (2020). Psychological processes underpinning least-worst option selection. Thinking \& Reasoning, 1(1), 118-139.

Shortland, N. D., Alison, L. J., \& Barrett-Pink, C. (2018). The military (in)decision making process: A Framework to investigate decision inertia in military operations. Theoretical Issues in Ergonomic Science doi:https://doi.org/10.1080/1463922X.2018.1497726

Shortland, N. D., Alison, L. J., \& Moran, J. (2019). Conflict: How soldiers make impossible decisions. New York, NY: Oxford University Press.
Shortland, N. D., Alison, L. J., \& Thompson, L. (2020). Military maximizers: Examining the effect of individual differences in maximization on military decision making. Personality and Individual Differences, 163. Advance online publication. doi:https://doi.org/ 10.1016/j.paid.2020.110051

Simons, L., Lathlean, J., Squire, C. (2008). Shifting the focus: sequential methods of analysis with qualitative data. Qualitative Health Research, 18(1), 120-132.

Sniezek, J. A., \& Van Swol, L. M. (2001). Trust and expertise in a judge advisor system. Organizational Behaviour and Human Decision Processes, 82, 288-307.

Tetlock, P. E., \& Boettger, R. (1989). Accountability: A social magnifier of the dilution effect. Journal of Personality and Social Psychology, 57, 388-398.

Todd, P. M., \& Gigerenzer, G. (2001). Putting naturalistic decision making into the adaptive toolbox. Journal of Behavioral Decision Making, 14(5), 381-383.

United States Army. (2015). The army human dimension strategy. United States Army.

van den Heuvel, C., Alison, L., \& Crego, J. (2012). How uncertainty and accountability can derail strategic 'save life' decisions in counterterrorism simulations: A descriptive model of choice deferral and omission bias. Journal of Behavioral Decision Making, 25, 165187.

Waring, S., Alison, L., Cunningham, S., \& Whitfield, K.C. (2013). The impact of accountability on motivational goals and the quality of advice provided in crisis negotiations. Psychology, Public Policy and Law, 19(2), 137-150.

Wong, W., \& Blandford, A. (2004). Describing situation awareness at an emergency medical dispatch centre. Proceedings of the Human Factors and Ergonomics Society's 48th Annual Meeting (pp. 285289). doi:https://doi.org/10.1177/154193120404800302

Publisher's note Springer Nature remains neutral with regard to jurisdictional claims in published maps and institutional affiliations. 